\title{
Emergency Information Sharing Mechanism and Efficiency Measurement in Coastal Cities, China
}

\author{
Xing Huang ( $\nabla$ huangxing6213@126.com ) \\ southwest university of science and technology https://orcid.org/0000-0003-4048-2473 \\ Jieru Huang \\ SWUST: Southwest University of Science and Technology
}

\section{Research Article}

Keywords: emergency information sharing mechanism, collaborative efficiency measurement, coupling degree model, coastal city

Posted Date: October 28th, 2021

DOl: https://doi.org/10.21203/rs.3.rs-863747/v1

License: (c) (i) This work is licensed under a Creative Commons Attribution 4.0 International License. Read Full License 


\title{
Emergency Information Sharing Mechanism and Efficiency Measurement in Coastal Cities, China
}

\author{
Xing Huang, Jieru Huang \\ School of Economics and Management, Southwest University of Science and Technology, \\ Mianyang, China, 621010 \\ ORCID: 0000-0003-4048-2473 \\ Address: 59th, Qinglong Avenue, Fucheng District, Mianyang City, Sichuan Province, China. \\ E-mail: huangxing6213@126.com, Phone No: +86 18381673380
}

\begin{abstract}
To establish and improve the theoretical framework and operation mechanism of emergency information sharing, and to establish the index system and evaluation method of the efficiency of emergency information sharing are the key work to improve the disaster prevention and mitigation capacity of coastal cities in China. In this paper, the synergetic theory is introduced into the construction of emergency information sharing framework. By clarifying the operation relationship between the participants and the information transmission, the framework and operation mechanism of emergency information sharing are constructed. Around the 3 dimensions of emergency information sharing mechanism construction, resource guarantee ability and collaborative driving force of emergency information sharing, the evaluation index system of emergency information sharing collaborative efficiency in coastal cities is proposed, and the evaluation method of emergency information sharing collaborative efficiency based on coupling degree model is proposed. The empirical results show that the efficiency of emergency information sharing in coastal cities in China is generally on the rise, and the contribution rate of the construction level of emergency information sharing mechanism is higher than that of the resource guarantee ability and the collaborative driving force of emergency information sharing, but the efficiency of emergency information sharing in coastal cities in China is still at the bottom level. The research results provide theoretical basis and methods for the emergency management departments of coastal cities in China.
\end{abstract}

Key words: emergency information sharing mechanism, collaborative efficiency measurement, coupling degree model, coastal city

\section{Introduction}

China's coastal cities are economically and population-intensive areas. In recent years, frequent public emergencies have seriously threatened the social and economic development of the coastal cities and the safety of people's lives and property, and have also presented severe challenges to the responses of governments at all levels in coastal cities. At present, the establishment of the National Emergency Management Department means that the pattern of fragmentation and low coordination in the past will be completely changed, with a view to enhancing the coordinated response capabilities of coastal cities for disaster prevention and reduction. Overall, China's coastal cities have achieved great improvement in their ability to coordinate disaster prevention and mitigation, and a comprehensive coordination and joint prevention and control mechanism has been basically formed. Especially in the process of disaster prevention and reduction, problems such as untimely information sharing, unclear information tasks and unsatisfactory operation mechanism of confidence sharing, etc., which have greatly restricted the efficiency and effectiveness of disaster prevention and reduction in coastal cities. Therefore, it is necessary to focus on the construction of information sharing mechanism for disaster prevention and mitigation in coastal cities, and 
fundamentally change the traditional supervision mode of emergency information relying on "command control".

In recent years, many scholars have carried out many studies around emergency information sharing, and their achievements have mainly focused on emergency information sharing collaborative research, emergency information sharing mechanism research, and emergency collaborative governance. In terms of collaborative research on emergency information sharing, it mainly focuses on the research of emergency information collaborative factors, collaborative framework and collaborative efficiency. Chen Yumei (2018) ${ }^{[1]}$ believes that the five aspects of support within the organization, coordination between organizations, legal protection and supervision incentives, and external environment are the key factors affecting the sharing of emergency information; Cheng Conghui (2015) ${ }^{[2]}$ using an interpretive structure model, a multi-layer hierarchical interpretive structure model that affects the effectiveness of emergency information command; Wang Bingbing et al. (2015) ${ }^{[3]}$ based on the theory of system dynamics, revealed that the level of emergency information sharing in online social networks is jointly affected by the three factors of government information transparency, netizen participation and online public opinion; Xiao Hua (2019) ${ }^{[4]}$ introduced the theory of collaboration to the co-construction and sharing of emergency information resources, and built a collaborative framework for the sharing of emergency information resources; Pan Bo et al. (2015) ${ }^{[5]}$ designed a four-in-one emergency information coordination mechanism of assets, capabilities, actions and coordination; Delone et al. $(1995)^{[6]}$ summarized the six dimensions of information system success: system quality, information quality, system use, personal impact, user satisfaction, and organizational impact; Kaur et al. $(2020)^{[7]}$ proposed an IoT-Fog-Cloud emergency information collaboration framework based on soft computing technology for real-time wildfire monitoring, prediction and forecasting. In the research of emergency information sharing mechanism, the most studied are emergency information sharing decision-making and operation mechanism. Zhang Zimin et al. (2010) ${ }^{[8]}$ constructed emergency response by analyzing the generation and characteristics of emergency information flow information model; Chen Yumei et al. (2017) ${ }^{[9]}$ put forward policy recommendations to improve the efficiency of emergency information sharing around the legal system, shared concepts, information technology and supervision and incentives; Wheaton (2001) ${ }^{[10]}$ analyzed the role of information in emergency decision-making from a strategic and tactical perspective; Dawes et al. (2004) ${ }^{[11]}$ research shows that in the emergency response process, the lack of information sharing and coordination will have a negative impact between departments; Netten (2006) ${ }^{[12]}$ research shows that: in the emergency response process, the huge amount of information will increase the complexity of information sharing, and there may be information load or lack of information during the information transmission; Ding et al. (2019) ${ }^{[13]}$ proposed a new integration method based on prospect theory and VIKOR (VIsekriterijumska optimizacija i KOm-promisno Resenje), called the language PT-VIKOR, which is used in emergency information sharing to solve the EDM problem with two-dimensional uncertain language information. Regarding the research on the operation mechanism of emergency information sharing, Deng Chunlin et al. (2014) ${ }^{[14]}$ took Hunan Province as an example, focusing on the information processing mechanism of emergencies, the early warning mechanism of public opinion, the transmission and reporting mechanism, the release and disclosure mechanism, the supervision and control mechanism and the security in terms of mechanisms, etc., a framework for sharing information resources for emergencies was constructed; Pan Bo et al. (2017) ${ }^{[15]}$ based on the information system success model (IS), studied the impact of emergency resource coordination on the construction of cross-department emergency information systems; Guo Lusheng et al. $(2016)^{[16]}$ established the overall framework and process of emergency information resource planning based on EA. In the research of emergency collaborative governance, Cheng Shunqi et al. 
(2019) ${ }^{[17]}$ introduced the theory of holistic governance and self-organization, constructed a multilevel, cross-department, and full-process emergency linkage disposal platform, and discussed the emergency management coordination mechanism; Cai Dongxue et al. (2017) ${ }^{[18]}$ compared the layout decision method and the hierarchical collaborative reserve layout method in the existing management model, and established a multi-objective multi-level collaborative layout model under scenario analysis; Lin Zhen (2019) ${ }^{[19]}$ studied the collaborative governance mechanism of emergency public opinion network composed of data, tools and business process reorganization to form a multi-agent system governance.

The above literature mainly studies the management of emergency information sharing from management, although there have been many discussions on the synergy of emergency information sharing, sharing influencing factors, sharing organizational structure and sharing efficiency, but these results are more focused on the discussion of macro-decisions, and their shortcomings are reflected in: First, the existing achievements are lack of systematization in general and a set of relatively systematic emergency information sharing mechanism is lack from the micro perspective. The description of the supply and demand subjects of emergency information resources is not clear; Second, the mechanism of emergency information sharing in coastal cities has its own characteristics. Most of the information resources come from marine disasters. It is necessary to build a set of emergency information sharing mechanism in line with the specific disasters in coastal cities. The existing research is lack of this aspect; The third is the lack of a set of measurement index systems and methods that can effectively evaluate the efficiency of emergency information sharing in coastal cities for disaster prevention and mitigation, making the emergency information sharing operation mechanism lacking evaluation basis. In view of this, this paper aims at the characteristics of coastal city disaster prevention and mitigation, from the perspective of synergy theory, by clarifying the relationship between the participants of emergency information sharing and information transmission, constructs an emergency information sharing framework and operation mechanism suitable for coastal city disaster prevention and reduction. On this basis, the measurement index system and evaluation method of emergency information sharing collaborative efficiency are further proposed, with a view to providing theoretical guidance and method support for the practice of disaster prevention and mitigation information management in coastal cities. The difference of this paper is that it proposes a coastal city emergency information sharing framework and operation mechanism based on the synergy theory, and proposes an index system and measurement method that affect the coastal city emergency information sharing collaboration efficiency.

\section{Emergency Information Sharing Framework Based on Collaboration Theory}

\subsection{Connotation of collaboration theory}

Synergetic theory was put forward by German physicist Herman Haken in 1976. Synergetic theory mainly studies how open systems far from equilibrium can spontaneously appear orderly structures in time, space and function through their own internal synergism when they have material or energy exchange with the outside world. Collaboration theory believes that although different systems have different attributes, there is a cooperative relationship between various systems in the entire environment; Whether the system can play the synergistic effect is determined by the synergy of the subsystems within the system. To promote the synergy of the subsystems, the system must be open and able to exchange energy and information with the outside world to ensure that the system has development capabilities. Collaboration theory believes that the system is a complex and open system. The complexity of the system is because the system is generally composed of three major elements: people, organizations and the environment. Each element is nested with multiple 
secondary elements, and its internal characteristics are nonlinear ${ }^{[20]}$. Synergy theoretically supports the orderly evolution of a composite system and could ensure that the elements of an open system become orderly in time, space and function at the macroscopic level during the exchange process of energy ${ }^{[21]}$. The purpose of collaborative theory research is to establish a method and concept to deal with complex systems with a system view. Collaboration theory can provide a theory and method for a decentralized and disorderly emergency management system, making it a virtuous circle of coordination, cooperation, and order.

\subsection{Elements of the emergency information sharing framework of coastal cities}

Based on the perspective of collaboration theory, the coastal city emergency information sharing framework is mainly composed of four elements: emergency information participants, emergency information resources, emergency behaviors, and software and hardware. These four elements form an organic whole that can achieve emergency efficiency and maximize benefits with the characteristics of subject coordination, sharing efficiency, and rapid response according to the rules of collaboration. The interrelationship is: emergency information participants and emergency information resources provide the basis for emergency behaviors. Emergency behaviors achieve the goals of emergency information participants and emergency information resources through the support of software and hardware resources (Figure 1). Among them, the participants of emergency information are composed of people and organizations that provide, process, analyze and use information. As far as coastal cities are concerned, they mainly include: government, port and shipping, maritime affairs, public security and fire protection, enterprises, social organizations, information management, and medical care. And other relevant organizations, as well as experts, rescue teams, the general public, military, media workers, technical personnel and other relevant personnel; Emergency information resources are composed of basic information resources, rescue information resources, and data streams. Basic information resources include five aspects: politics, economy, social development, resources, environment, and geographic information. Emergency information resources include disaster information, emergency plans, and emergency response. Et al. (Kou Youguan, 2005) ${ }^{[22]}$; Emergency behaviors include disaster reporting, determination of plans, material financing and deployment, disaster relief and recovery, etc.; hardware and software resources include facilities and equipment for storage, reception, processing, and transmission of emergency information, and decision-making systems and assistance to support emergency operations Platforms and management systems, etc. (Xiao Hua et al., 2015) ${ }^{[23] .}$ 


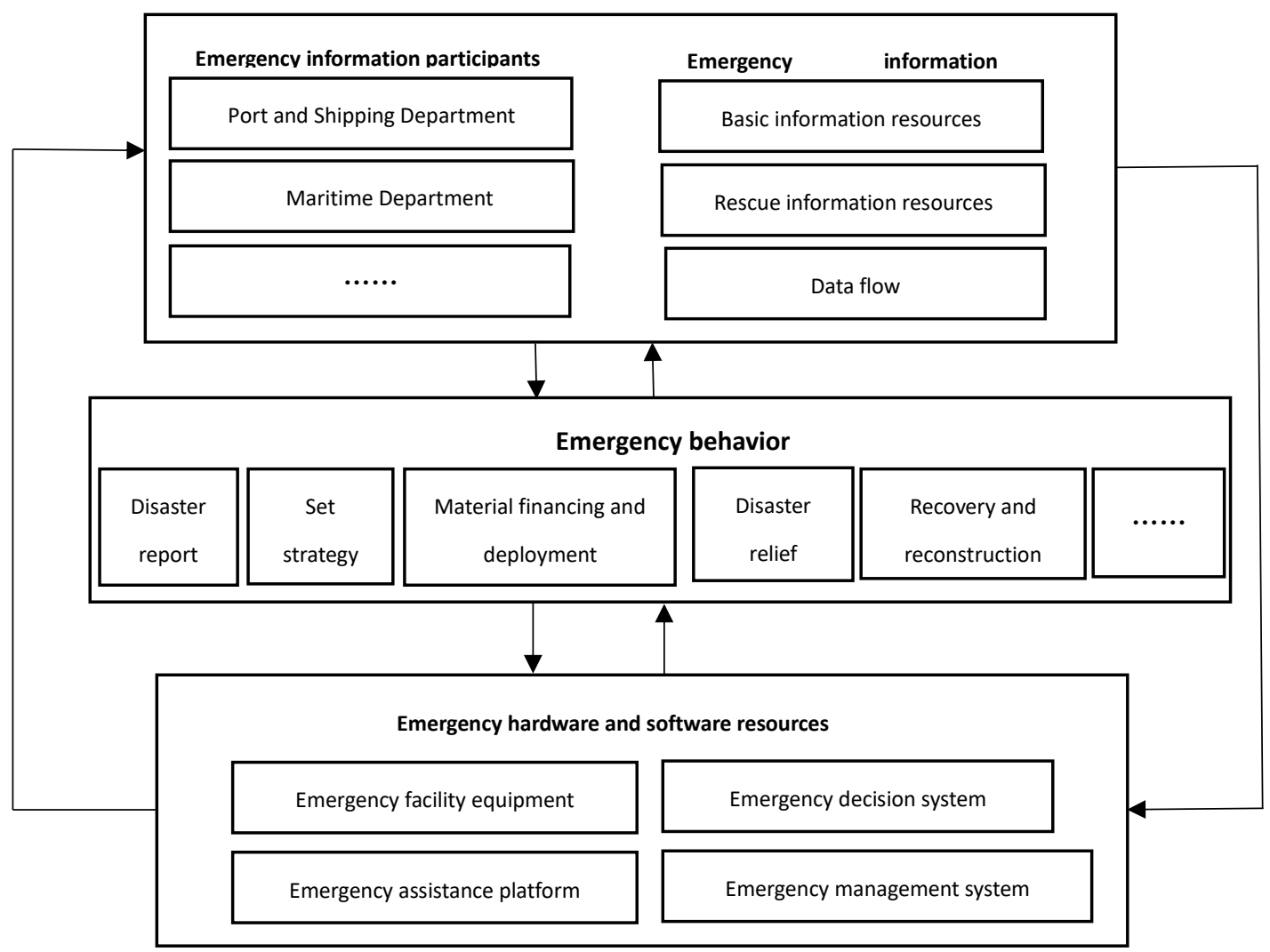

Fig. 1 The relationship between emergency information participants, emergency information resources, emergency behaviors, and hardware and software

\subsection{Coastal city emergency information sharing framework based on synergy theory}

At present, there are many problems in the emergency information sharing process in China's coastal cities. According to the Emergency Response Law of the People's Republic of China, China's emergency response mainly adopts a two-level model of emergency command centers and emergency response departments, and the emergency command center mainly implements the intelligence of emergency decision-making and command coordination. The emergency response department is mainly responsible for executing the emergency tasks and its responsibilities issued by the command center. It belongs to the centralized management and decentralized implementation of the response mode, which can be described by Figure 2 . 


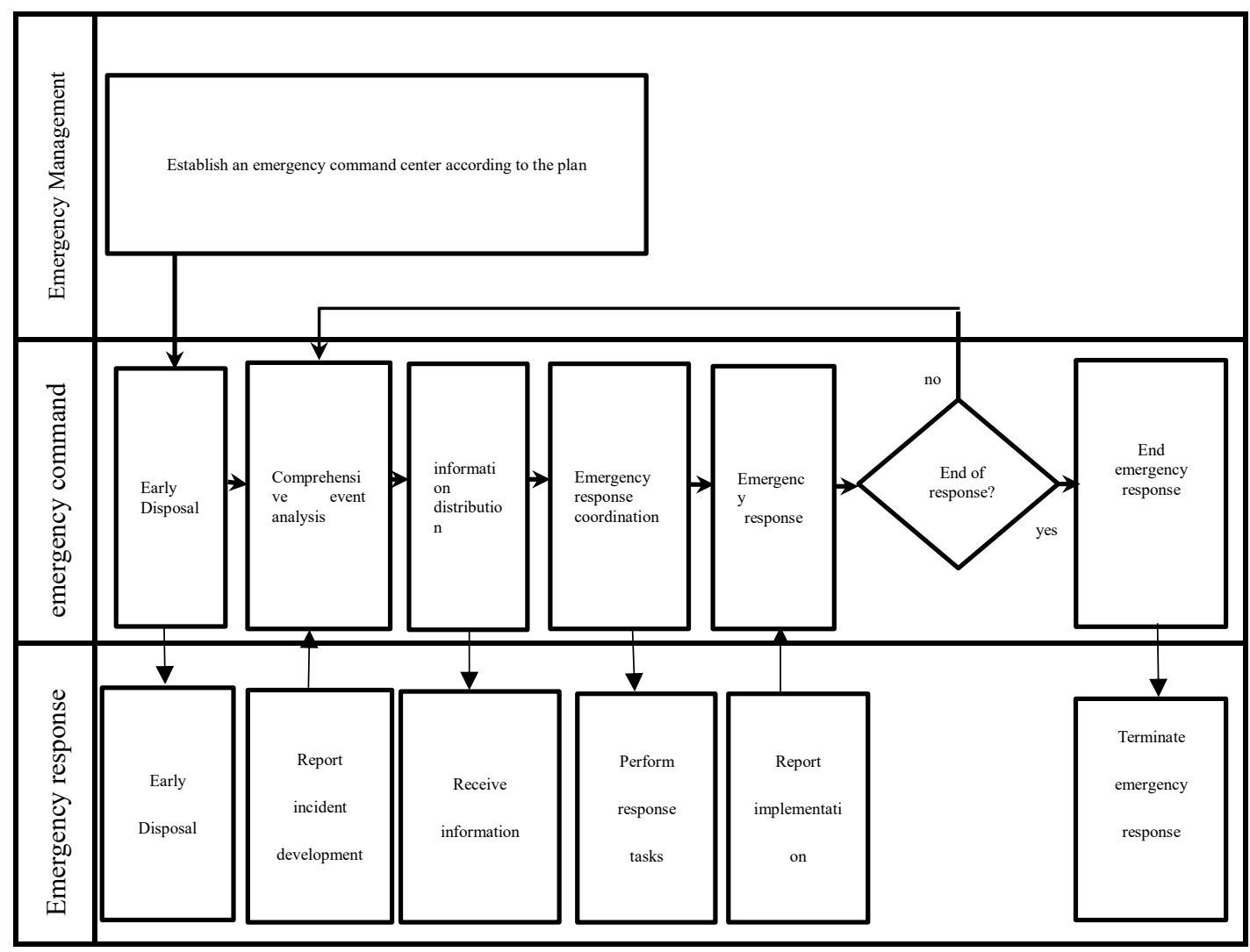

Fig. 2 Emergency information response process in two-level mode

The advantage of the two-level response mode in Figure 2 is that it can effectively guarantee the efficient and unified command of decision-making, but the disadvantage is that: First, in the process of emergency information sharing, it is easy to have poor communication between the emergency subject and the public, and the emergency command organization has no clear demand for user information; Second, the emergency participants are independent of each other, and the collection, processing, transmission, and feedback mechanisms of emergency information are not conducive to collaboration between the two levels of departments; The third is that the emergency response department is not active, relying on the decision and instructions of the emergency command center, and the efficiency of information collection, disposal and feedback is low. The idea of the synergy theory lies in the diversification of the main body and the synergy of the cooperation methods. Its purpose is to maximize the value of resource utilization and service quality by integrating multiple resources, which provides a theoretical basis for the synergy of emergency information sharing in coastal cities in China. In Figure 1 above, the three elements of emergency information participants, emergency information resources, and emergency software and hardware resources ultimately provide support for emergency behaviors, and achieve disaster prevention and mitigation goals through emergency behavior. However, the execution effect of emergency behaviors is affected by emergency information participants, emergency information resources, and hardware and software. Emergency information participants are the performers and decision makers of emergency behaviors. The synergy of the two will affect the efficiency of emergency behaviors, and the efficiency of emergency behaviors is affected by the degree of information sharing, information coverage, information processing capabilities and decision effectiveness, only when they cooperate with each other and respond in a coordinated manner can the level of emergency information sharing be promoted. Therefore, the prerequisite for improving the level of emergency information sharing in coastal cities is to build a coordinated and effective information resource sharing network. Such a network should be composed of the main body of emergency response information generation, management and use, and information transmission channels, management platforms, software and hardware, etc. Co-participate in a shared collaborative system with networked, integrated, and 
digital features to achieve cross-platform, cross-department, and cross-regional information collaboration services. This article is based on the synergy theory and on the basis of reference [4], proposes the emergency information sharing framework shown in Figure 3.

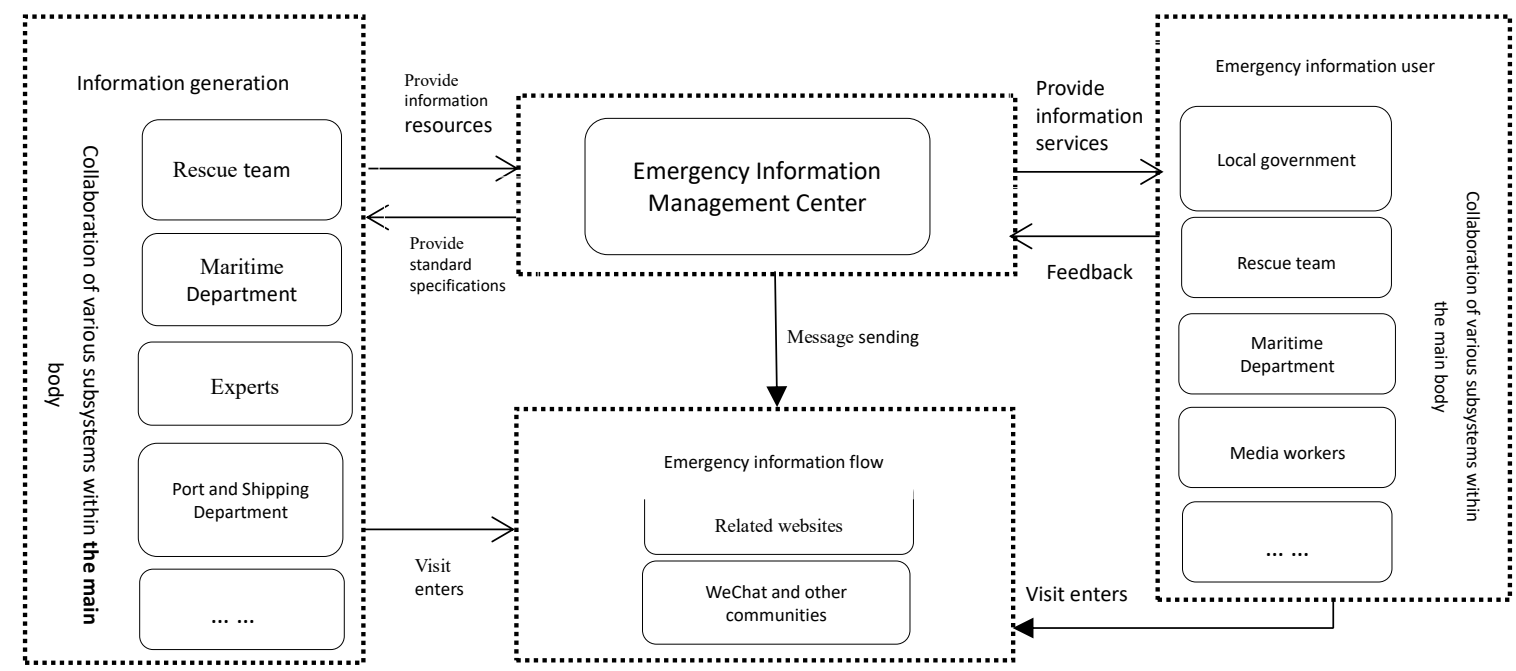

Fig. 3 Coastal city disaster prevention and mitigation emergency information sharing framework based on collaboration theory

Figure 3 improves the traditional response model of centralized management and decentralized implementation into an emergency information sharing model of centralized management, decentralized implementation, subject coordination, and joint participation. This new sharing model is beneficial to make up for the information islands, The lack of a single source of information and the inadequacy of the information supervision mechanism have effectively realized the coconstruction and sharing and efficient collaboration of disaster prevention and mitigation emergency information in coastal cities.

\section{(1) Operating mechanism of emergency information sharing framework from a collaborative perspective}

The main body of emergency information generation and use of emergency information in Figure 3 includes government agencies, non-governmental organizations, enterprises and institutions and expert groups, the public, rescue teams, media and other related organizations and individuals. The emergency information management center is the core organization for sharing emergency information in coastal cities. It is mainly responsible for the formulation of emergency information disposal standards, emergency information services, distribution and comprehensive management. The emergency information management center will provide the processed emergency information resources to the emergency information use subject, and the emergency information use subject will feed back the information to the emergency information management center according to the decision-making needs and execution needs. The available shared information is formed, and the emergency information management center sends the shared information to the media in a unified manner for all subjects and people to access. The entire operation process not only embodies centralized management and decentralized implementation, but also embodies the coordination and joint participation of the subjects.

\section{(2) Establish a coordinated and standardized platform for emergency information sharing}

The function of the emergency information sharing collaborative standardization platform is to synthesize the information of different departments, different regional platforms and various types 
of users, and make emergency decisions based on the recommendations of expert groups. Through the emergency information sharing collaborative platform, users can conduct a one-stop search and can support each coastal city to provide emergency information sharing services to the user body. The standardized platform for emergency information sharing mainly integrates various local governments, maritime departments, port and shipping departments, public security and fire protection, enterprises, non-social organizations and other emergency information participants in coastal cities. Standardize information resources and information services through a standardized platform, including information resource management standards, information security technology standards, information conversion standards, system integration standards, system operation standards, and information service standards, etc. The purpose is to break the pattern of individualism.

\section{(3) Establish a collaborative communication model for emergency information}

The collaborative communication of emergency information involves the entire emergency management area of the coastal city. It is different from the traditional single-media independent communication mode. It requires the close cooperation and joint efforts of the relevant departments of the entire coastal city. In terms of establishing inter-departmental coordination and cooperation, accomplish tasks that cannot be completed by a single coastal city. In order to establish an emergency information collaborative dissemination model, it is necessary to reform the traditional emergency information dissemination model, break the boundaries between departments, enter emergency information into meta data according to the sharing standard, and establish shared links between departments and websites. By establishing an emergency information collaborative communication model, the sharing of emergency information resources in coastal cities will be gradually realized.

\section{(4) Establish a collaborative management model for emergency information resources}

The collaborative management mode of emergency information resources based on the collaboration theory mainly starts from establishing the emergency knowledge element link mode, and describes emergency information by means of knowledge elements. The coordination of emergency information resources can be reflected as the content coordination between emergency knowledge elements; Then, the constantly updated, massive, and constantly emerged emergency knowledge elements are built into the emergency knowledge meta-database, and then the emergency knowledge meta-database is embedded into various databases. Through this process, the emergencies knowledge database can embed the database and the emergency information between the platforms is related according to the content, forming an organic whole ${ }^{[24]}$. On this basis, a hierarchical and modular approach is used to divide the emergency information resources into a multi-knowledge element and multi-level emergency information resource management system to realize the cross-domain of the emergency information resource collaborative management model based on the emergency knowledge element ${ }^{[25]}$.

\section{Coastal city emergency information sharing collaborative efficiency measurement}

\subsection{Measurement index of emergency efficiency of emergency information sharing}

This paper proposes the basis for measuring the efficiency index of coastal city emergency information sharing collaboration as follows: 
The theory has been widely used in the research of information technology, information system and information sharing among organizations ${ }^{[26-27]}$. Coastal city emergency information sharing belongs to the inter-organization, inter-department and inter-regional linkage behavior. It is a kind of innovation behavior spread among organizations, departments and regions. It is reasonable to use innovation communication theory as the basis for obtaining indicators.

\section{(2) Based on existing research results}

The research results of Hu Ping (2007) ${ }^{[28]}$, Sharon S (1996) ${ }^{[29]}$, David L (2001) $)^{[30]}$, and Chen Yumei (2017) were used in the proposed index for measuring the efficiency of emergency information sharing collaboration.

(3) Based on in-depth interviews with coastal city emergency management departments, port and shipping departments, and maritime departments

Through in-depth interviews with relevant departments in 6 coastal cities, including the Haikou Municipal Port and Shipping Bureau, the Shanghai Emergency Management Bureau, and the Fuzhou Maritime Safety Bureau, the commonality of emergency information sharing efficiency measurement indicators was summarized.

\section{(4) Measurement index screening and weighting}

\section{1) Reliability test of measurement index}

Bartlett's spherical test and KMO (Kaiser-Meyer-Olkin) test are performed on the measurement index to determine whether the data of the measurement index meet the conditions of factor analysis. As shown in Table 1, the KMO value of the measurement index after the initial screening was $0.771>$ 0.5 , Sig. $=0<0.05$, indicating that the measurement indicators after the initial screening meet the conditions of factor analysis.

Table $1 \mathrm{KMO}$, Bartlett test to evaluate the measurement index after the primary selection

\begin{tabular}{ccc}
\hline KMO inspection & & 0.812 \\
\hline \multirow{3}{*}{ Bartlett sphericity } & Chi-square test & 7.771 \\
& df & 32 \\
& Sig. & 0.000 \\
\hline
\end{tabular}

\section{2) Factor principal component analysis}

Principal component analysis is performed on the initially determined measurement index, and the factor with a cumulative contribution rate of $85 \%$ is used as the final measurement index.

\section{3) Measure index weight}

The expert assignment method is used to analyze the correlation between the measurement index and the evaluation object to provide data support for determining the weight of the measurement index. This paper uses Likert's 5-level scale method to assign values to the measurement indicators: "strong correlation" = 5, "high correlation" = 4, "general" = 3, "weak correlation" = 2, "uncorrelated" 
$=1$. Using the coefficient of variation method to determine the weight of the measurement index, the steps are as follows:

Step 1: After preprocessing the original data, calculate the mean and standard deviation of each measurement index.

Step 2: Calculate the coefficient of variation of each measurement index based on the mean and standard deviation according to formula (1).

$$
v_{i}=\frac{\partial_{i}}{\bar{x}_{i}}
$$

Where $v_{i}$ is the coefficient of variation of the $\mathrm{i}$-th measurement index, $\partial_{i \text { is }}$ the standard deviation of the $\mathrm{i}$-th measurement index, and $\bar{x}_{i \text { is }}$ the average score of the $\mathrm{i}$-th measurement index.

Step 3:Calculate the sum of coefficients of variation of each measurement index according to formula (2).

$$
\mathrm{A}=\sum_{i=1}^{n} v_{i}, \quad i=1,2, \ldots, n
$$

Step 4: Calculate the weight of each measurement index according to formula (3). The weight of each measurement index is equal to the ratio of the coefficient of variation of the measurement index and the coefficient of variation.

$$
w_{i}=\frac{v_{i}}{A}
$$

\begin{tabular}{|c|c|}
\hline Dimension & Impact factor \\
\hline \multirow{6}{*}{$\begin{array}{l}\text { Construction level of emergency } \\
\text { information sharing mechanism }\end{array}$} & Emergency information collection and processingC $\mathrm{C}_{11}(0.201)$ \\
\hline & Emergency information report $\mathrm{C}_{12}(0.170)$ \\
\hline & Emergency information disclosure $\mathrm{C}_{13}(0.181)$ \\
\hline & Emergency information supervision and regulation $\mathrm{C}_{14}(0.132)$ \\
\hline & Emergency information security $\mathrm{C}_{15}(0.135)$ \\
\hline & Emergency information sharing incentives $\mathrm{C}_{16}(0.181)$ \\
\hline \multirow{5}{*}{$\begin{array}{l}\text { Emergency information sharing } \\
\text { resource support capability }\end{array}$} & Emergency information technology and equipmentC $\mathrm{C}_{21}(0.277)$ \\
\hline & Completeness of policies and regulations $\mathrm{C}_{22}(0.264)$ \\
\hline & Uniformity of emergency information standardsC $23 \quad(0.281)$ \\
\hline & Capital guarantee $\mathrm{C}_{24}(0.178)$ \\
\hline & Clear management function positioning $\mathrm{C}_{31}(0.257)$ \\
\hline \multirow{3}{*}{$\begin{array}{l}\text { Synergistic driving force for } \\
\text { emergency information sharing }\end{array}$} & Emergency information service satisfactionC $\mathrm{C}_{32}(0.167)$ \\
\hline & Barriers to emergency information sharingC $\mathrm{C}_{33}(0.310)$ \\
\hline & $\begin{array}{l}\text { Emergency management organization integration capabilities } \mathrm{C}_{34} \\
\qquad(0.266)\end{array}$ \\
\hline
\end{tabular}

According to the above methods, the indicators and weights for the collaborative efficiency of emergency information sharing in coastal cities were finally determined, as shown in Table 2.

\subsection{Method for measuring collaborative efficiency of emergency information sharing ${ }^{[31]}$}

This paper uses the coupling theory in physics to quantitatively evaluate the collaborative efficiency of emergency information sharing in coastal cities. Coupling theory advocates using the degree of coupling to measure the level of coordination among various factors within the system ${ }^{[32]}$, which is similar to the coordination between various measurement indicators in the coastal city information sharing system. Therefore, this paper uses the coupling degree in physics to evaluate the efficiency of emergency information sharing and collaboration in coastal cities. 
The three dimensions in Table 1 are regarded as subsystems. Firstly, the contribution of each measurement index to the subsystem is determined, and Let the variable $U_{i}(i=1,2, \ldots, n)$ be the sequence parameter for the measurement of the coordinated efficiency of emergency information sharing in coastal cities, that is, the subsystem of "construction level of emergency information sharing mechanism", the subsystem of "support capacity of emergency information sharing resources" "Emergency Information Sharing Collaborative Driving Force" subsystem, then the emergency information sharing collaborative efficiency function is:

$$
U_{i j}=\left\{\begin{array}{ll}
\frac{\left(\mathrm{x}_{\mathrm{ij}}-\beta_{\mathrm{ij}}\right)}{\alpha_{\mathrm{ij}}-\beta_{\mathrm{ij}}}, & \mathrm{U}_{\mathrm{ij}} \text { is positive efficiency } \\
\frac{\left(\alpha_{\mathrm{ij}}-\mathrm{X}_{\mathrm{ij}}\right)}{\alpha_{\mathrm{ij}}-\beta_{\mathrm{ij}}}, & \mathrm{U}_{\mathrm{ij}} \text { is negative efficiency }
\end{array}, \quad i=1,2, \ldots, n ; j=1,2, \ldots, m\right.
$$

In formula (4), $U_{i j}$ is the $\mathrm{j}$-th measurement index of the $i$-th order parameter, and its value $X_{i j}, X_{i j}$ reflects the satisfaction of each measurement index in each subsystem to achieve the target efficiency, ranging from 0 to 1 , approaching 0 is the most dissatisfied, approaching 1 is the most satisfactory; $\alpha_{i j}, \beta_{i j}$ is the upper and lower limits of the order parameters at the critical point of system stability.

The overall efficiency of each subsystem is calculated using the linear weighting method:

$$
U_{i}=\sum_{j=1}^{m} w_{i j} U_{i j}
$$

Among them, $w_{i j}$ is the weight of the $\mathrm{j}$-th measurement index in the $i$-th subsystem, $U_{i}$ is the contribution of each subsystem to the order of the total system, and $m$ is the number of measurement indexes in each subsystem.

\section{(2) The total efficiency of emergency information sharing and coordination in coastal cities}

According to the coupling degree model in physics, the measurement function of the cooperative efficiency of the three subsystems is:

$$
\mathrm{C}=\sqrt[3]{\left(u_{1} u_{2} u_{3}\right) /\left(u_{1}+u_{2}\right)\left(u_{2}+u_{3}\right)\left(u_{3}+u_{2}\right)}
$$

In formula (6), the value of $\mathrm{C}$ is between 0 and 1 . When $\mathrm{C}=0$, it indicates that the coordination efficiency between the subsystems is extremely small and is in an irrelevant state; when $\mathrm{C}=1$, it indicates high coordination efficiency between subsystems.

The total efficiency of formula (6) is of great significance for judging the efficiency intensity among the three subsystems, but the collaborative efficiency of formula (6) is difficult to reflect the contribution of all subsystems to the entire system, and relying solely on synergy efficiency to determine the magnitude of the synergy efficiency of the entire system may cause errors, because when the development level of the subsystem is low, its total synergy efficiency may be high. Therefore, we need to improve equation (6) to reflect the true synergy efficiency of the subsystem to the entire system:

$$
\left\{\begin{array}{c}
F=p_{1} u_{1}+p_{2} u_{2}+p_{3} u_{3} \\
C=\sqrt[3]{\left(u_{1} u_{2} u_{3}\right) /\left(u_{1}+u_{2}\right)\left(u_{2}+u_{3}\right)\left(u_{3}+u_{2}\right)} \\
H=\sqrt{C \cdot F}
\end{array}\right.
$$

Among them, $\mathrm{F}$ is the comprehensive development index, considering the difference of the important level contributed by each subsystem, p1, p2, p3 are the weighting coefficients, and the general value is 0.333 ; $\mathrm{H}$ is the modified synergy efficiency value, which combines the total synergy efficiency level C and Development Index F. 
In order to clarify the collaborative efficiency level of emergency information sharing in coastal cities, this paper refers to the hierarchical classification method proposed by Su Yi et al. (2018) to divide the $\mathrm{H}$ value into 4 levels ${ }^{[33]}$, as shown in Table 3 .

Table 5 Emergency information sharing coordination efficiency level

\begin{tabular}{ccccc}
\hline $\mathrm{H}$ & {$[0,0.4)$} & {$[0.4,0.6)$} & {$[0.6,0.8]$} & $(0.8,1)$ \\
\hline Efficiency class & low & medium & high & Extremely high \\
\hline
\end{tabular}

\section{Empirical analysis}

\subsection{Data acquisition}

In this paper, 13 disaster events that occurred in coastal cities in China in the past 20 years are selected as samples, as shown in Table 6. Because most of the measurement indicators are qualitative indicators, it is difficult to obtain data through monitoring equipment, so the method of expert assignment is used to obtain the original data, and the method of 5-level quantity is used to assign values to each measurement indicator: "Good" = 5, "Better" = 4. "General" = 3, "Poor" = 2, "Bad" $=1.45$ experts were invited, including 6 maritime department management personnel, 10 emergency management personnel, 6 port management personnel, and 23 experts and scholars. Cronbach a coefficient and Bartlett test were used to test the reliability and validity of the sample data. The results show that the sample data assigned by experts can objectively reflect the attributes of 13 disaster events. The final score of each measurement index is counted according to the mode.

Table 613 disaster events in coastal cities of China in the past 20 years

\begin{tabular}{|c|c|c|c|c|}
\hline $\begin{array}{l}\text { Serial } \\
\text { number }\end{array}$ & $\begin{array}{l}\text { Type of } \\
\text { disaster }\end{array}$ & $\begin{array}{c}\text { Time of } \\
\text { occurrence }\end{array}$ & Disaster Covered City & Disaster situation \\
\hline 1 & Red tide & May 10 & Ningbo & Affected sea area $100 \mathrm{~km}^{2}$ \\
\hline 2 & typhoon & August 1 & Xiangshan & $\begin{array}{l}\text { Wind power level 12, } 278.8 \text { thousand acres of } \\
\text { affected farmland, } 3625 \text { people were killed and } \\
\qquad 3825 \text { people were injured }\end{array}$ \\
\hline 3 & typhoon & September 3 & Lianjiang & $\begin{array}{l}\text { Wind power level 10, } 4.116 \text { million mu of affected } \\
\text { farmland, } 134 \text { deaths }\end{array}$ \\
\hline 4 & typhoon & August 24 & Putuo & $\begin{array}{l}\text { Wind power level 12, } 1.007 \text { million mu, } 18 \text { people } \\
\text { killed and } 55 \text { injured }\end{array}$ \\
\hline 5 & Red tide & May 11 & East of Ningbo Nantian Island & The affected sea area is about $2000 \mathrm{~km}^{2}$ \\
\hline 6 & Red tide & June 1-5 & $\begin{array}{l}\text { The waters near the Yushan } \\
\text { Islands }\end{array}$ & Affected sea area is $1000 \mathrm{~km}^{2}$ \\
\hline 7 & Red tide & June 7 & Xiangshan near shore & Affected sea area is $1000 \mathrm{~km}^{2}$ \\
\hline 8 & $\begin{array}{l}\text { Heavy } \\
\text { rain }\end{array}$ & August 9-11 & Zhanjiang, Maoming, Meizhou & $\begin{array}{l}1.165 \text { million people were affected and } 3665 \text { houses } \\
\text { collapsed }\end{array}$ \\
\hline 9 & Red tide & June 9 & $\begin{array}{l}\text { Songlan Mountain to Tantou } \\
\text { Mountain }\end{array}$ & Affected sea area $1600 \mathrm{~km}^{2}$ \\
\hline 10 & $\begin{array}{l}\text { Heavy } \\
\text { rain }\end{array}$ & May 7 & Guangzhou & $\begin{array}{l}109 \text { houses collapsed, } 256,800 \mathrm{mu} \text { of farmland was } \\
\text { submerged, 32,166 people were affected, } 6 \text { died, } \\
\text { and the direct economic loss was } 543.8 \text { million } \\
\text { yuan }\end{array}$ \\
\hline 11 & $\begin{array}{l}\text { Storm } \\
\text { surge }\end{array}$ & October $11-12$ & $\begin{array}{l}\text { Hebei Province, Tianjin City, } \\
\text { Shandong Province }\end{array}$ & $\begin{array}{l}\text { Direct economic loss of } 1.3 \text { billion yuan, } 200,000 \\
\text { people affected by the disaster }\end{array}$ \\
\hline 12 & $\begin{array}{l}\text { Storm } \\
\text { surge }\end{array}$ & March 4 & $\begin{array}{c}\text { Weihai, Yantai, Weifang, } \\
\text { Qingdao, Binzhou, Dongying }\end{array}$ & $\begin{array}{l}\text { Direct economic loss of } 1.927 \text { billion yuan, } 3 \\
\text { deaths, } 7 \text { missing }\end{array}$ \\
\hline
\end{tabular}




\begin{tabular}{|c|c|c|c|c|}
\hline 13 & $\begin{array}{l}\text { Storm } \\
\text { surge }\end{array}$ & September 19 & $\begin{array}{l}\text { Zhuhai, Zhongshan, Jiangmen, } \\
\text { Yangjiang, Zhanjiang, Maoming }\end{array}$ & $\begin{array}{l}6.52 \text { million people were affected, } 26 \text { people were } \\
\text { killed and missing, 15,322 houses collapsed, and } \\
\text { direct economic loss was } 11.38 \text { billion yuan }\end{array}$ \\
\hline
\end{tabular}

According to the synergy efficiency measurement method in Section 3.2, the contribution level of each subsystem's order parameter, the comprehensive index F, the system's total synergy efficiency $\mathrm{C}$, and the modified system efficiency $\mathrm{H}$ are calculated in sequence. Since the three subsystems are equally important, the values of $\mathrm{p} 1, \mathrm{p} 2$, and $\mathrm{p} 3$ are 0.333 , and the calculation results are shown in Table 7.

Table 7 Collaborative efficiency of emergency information sharing for 13 disaster events in coastal cities in

\begin{tabular}{|c|c|c|c|c|c|c|}
\hline \multirow[b]{2}{*}{$\begin{array}{l}\text { Serial } \\
\text { number }\end{array}$} & \multicolumn{5}{|c|}{ China } & \multirow[b]{2}{*}{$\begin{array}{c}\text { Modified } \\
\text { collaborative } \\
\text { efficiency H }\end{array}$} \\
\hline & $\begin{array}{c}\text { Emergency } \\
\text { information } \\
\text { sharing } \\
\text { mechanism } \\
\text { disaster } \\
\text { reduction level } \\
\text { U1 }\end{array}$ & $\begin{array}{c}\text { Emergency } \\
\text { information } \\
\text { sharing resource } \\
\text { support } \\
\text { capability U2 }\end{array}$ & $\begin{array}{c}\text { Emergency } \\
\text { information } \\
\text { sharing } \\
\text { collaborative } \\
\text { promotion } \\
\text { capability U3 }\end{array}$ & $\begin{array}{l}\text { Comprehensive } \\
\text { Development } \\
\text { Index F }\end{array}$ & $\begin{array}{l}\text { Overall system } \\
\text { coordination } \\
\text { efficiency C }\end{array}$ & \\
\hline 1 & 0.078 & 0.156 & 0.172 & 0.135 & 0.090 & 0.110 \\
\hline 2 & 0.312 & 0.417 & 0.192 & 0.307 & 0.219 & 0.259 \\
\hline 3 & 0.089 & 0.332 & 0.467 & 0.296 & 0.244 & 0.269 \\
\hline 4 & 0.267 & 0.231 & 0.189 & 0.229 & 0.165 & 0.194 \\
\hline 5 & 0.478 & 0.329 & 0.172 & 0.326 & 0.222 & 0.269 \\
\hline 6 & 0.648 & 0.099 & 0.219 & 0.322 & 0.173 & 0.236 \\
\hline 7 & 0.389 & 0.098 & 0.319 & 0.269 & 0.195 & 0.229 \\
\hline 8 & 0.178 & 0.091 & 0.319 & 0.196 & 0.158 & 0.176 \\
\hline 9 & 0.419 & 0.315 & 0.091 & 0.275 & 0.150 & 0.203 \\
\hline 10 & 0.538 & 0.458 & 0.510 & 0.502 & 0.504 & 0.503 \\
\hline 11 & 0.610 & 0.309 & 0.698 & 0.539 & 0.573 & 0.556 \\
\hline 12 & 0.289 & 0.319 & 0.107 & 0.238 & 0.140 & 0.183 \\
\hline 13 & 0.427 & 0.710 & 0.300 & 0.479 & 0.389 & 0.431 \\
\hline
\end{tabular}

\subsection{Results analysis and policy recommendations}

\section{(1) The overall efficiency of China's coastal cities' emergency information sharing is low}

The revised collaborative efficiency in Table 7 is classified according to the classification criteria in Table 5. The results show that the revised collaborative efficiency levels of Event 10, Event 11 and Event 13 are medium, and their revised collaborative efficiency values are 0.503, 0.556 and 0.431 , respectively. The coordination efficiency of the remaining 11 disaster events is of low grade, with the highest revised coordination efficiency value of 0.269 and the lowest of 0.110 , indicating that the collaborative efficiency of emergency information sharing in coastal cities in China is generally of low to medium grade, as shown in Figure 4. 


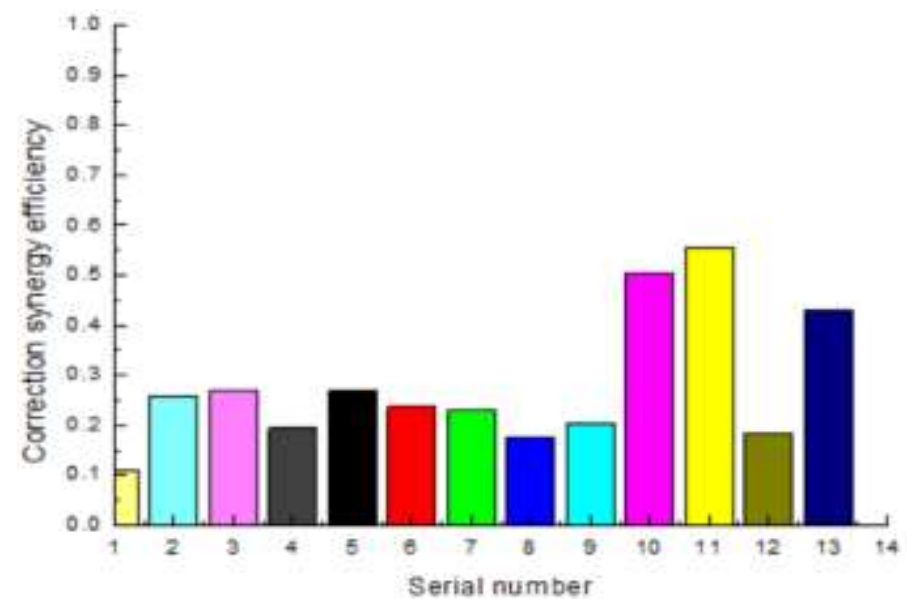

Fig. 4 Modified collaboration efficiency of emergency information sharing collaboration

\section{(2) The contribution level of each subsystem has gradually increased}

The 13 events in Table 7 are arranged in the order of occurrence time, and the calculation results show that: overall, the contributions of the "U1 = emergency information sharing mechanism construction level" subsystem, the "U2 = emergency information sharing resource support capability" subsystem, and the "U3 = emergency information sharing collaborative driving force" subsystem have increased smoothly. It shows that with the improvement of the disaster prevention and mitigation capabilities of coastal cities in China, the emergency information sharing and coordination capabilities are also increasing year by year, as shown in Figure 5.

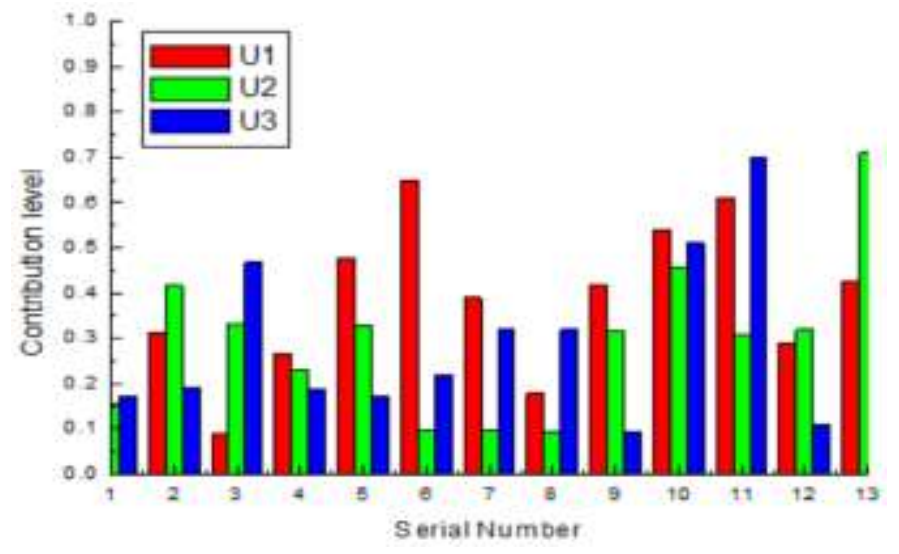

Fig. 5 Contribution level trend of each subsystem

\section{(3) The contribution levels of the three subsystems are uneven}

The average contribution level of the U1 subsystem among the three subsystems is 0.363 higher than the average contribution level of the U2 and U3 subsystems, indicating that the construction level of the emergency information sharing mechanism has increased significantly and plays a key role in the total contribution. The contribution level is still low (As shown in Figure 6), with an average contribution rate of only 0.316 . 


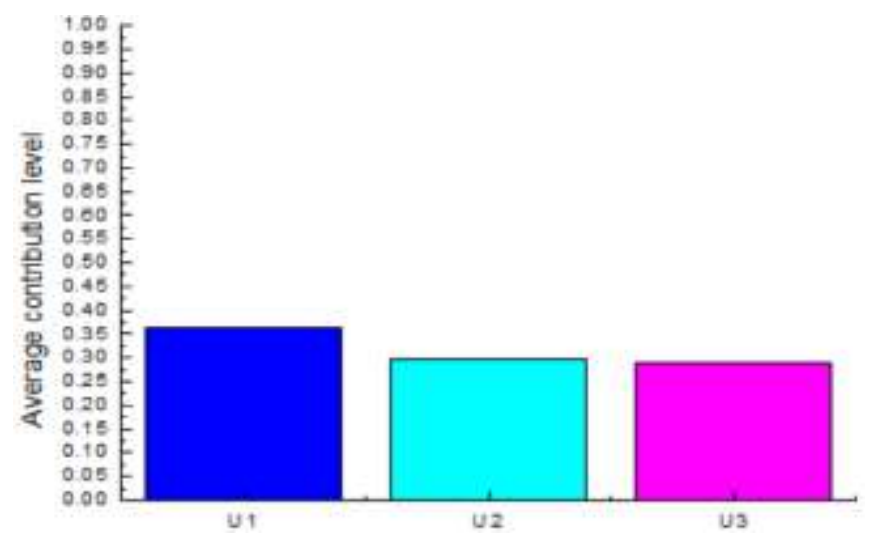

Fig. 6 Comparison of the average contribution level of each subsystem

Policy suggestion: The above analysis results show that the overall low efficiency of emergency information sharing collaboration in coastal cities in China is due to the low level of emergency information sharing mechanism construction, weak emergency information sharing resource support capabilities, and insufficient emergency information sharing synergy.

\section{(1) Speed up the construction of emergency information sharing mechanism system in coastal cities}

Focus on strengthening emergency information collection and processing, emergency information sharing incentives, emergency information disclosure and reporting mechanism construction, improve emergency information supervision and regulation capabilities, and strengthen emergency information security guarantee measures;

\section{(2) Enhance the emergency shared resources guarantee capability of coastal cities}

Accelerate the formulation of emergency information standards, improve relevant information management policies and regulations, and improve emergency information processing technology and hardware and software equipment;

(4) Comprehensively accelerate the construction of a coordinated driving force for emergency information sharing in coastal cities

Accelerate research on safeguards to reduce barriers to emergency information sharing, clarify emergency information management functions, accelerate the integration of institutions across departments and cities, and increase emergency information service satisfaction.

\section{Conclusions}

Aiming at the problem of emergency information sharing mechanism and collaborative efficiency measurement in the coordinated management of disaster prevention and mitigation in coastal cities, a theoretical framework and operation mechanism of emergency information sharing based on the collaborative theory are proposed, and It also proposes the measurement index system and measurement method of coastal city emergency information sharing collaborative efficiency around the construction of coastal city emergency information sharing mechanism, resource guarantee capability and emergency information sharing synergy.

(1) Established the theoretical framework and operation mechanism of emergency information sharing in coastal cities 
Introduce the theory of synergetic into the construction of emergency information sharing framework, by clarifying the operational relationship between the participants of emergency information sharing and information transmission, construct an emergency information sharing framework and operation mechanism suitable for the actual disaster prevention and reduction of coastal cities.

(2) Put forward an index system for measuring the efficiency of collaborative emergency information sharing in coastal cities

Based on the innovation communication theory, existing research results and extensive interviews, around the three dimensions of emergency information sharing mechanism construction, resource support capabilities and emergency information sharing synergy, through the selection of indicators. I propose that I can effectively evaluate emergency information index system for sharing collaborative efficiency.

(3) Propose a method for measuring the collaborative efficiency of emergency information sharing in coastal cities based on the coupling degree model

With the help of the coupling theory in physics, through the evaluation of the contribution level of each subsystem and the modified coordination efficiency of the entire system, it is found that the efficiency of emergency information sharing in coastal cities in China is on the rise, and the contribution rate of the level of emergency information sharing mechanism construction is higher than the resource guarantee capability. Synergy with emergency information sharing. But overall, the efficiency of China's coastal cities in emergency information sharing is still at a low to medium level.

To a certain extent, this paper enriches the research content of emergency management, but in order to avoid the difficulty of obtaining monitoring data, the method of expert assignment is used to obtain the data of measurement indicators, which to a certain extent affects the credibility of the evaluation results, which needs to be further studied.

\section{Acknowledgement}

This article is funded by the National Social Science Foundation of China (18XGL016), thanks to the review experts and editors of this article, and to the Chinese Ministry of Natural Resources and other government agencies that provide data support for this article. All data, models, and code generated or used during the study appear in the submitted article.

\section{References:}

[1] Chen Yumei, 2018, Analysis of key influencing factors of information sharing in emergency management collaboration under collaborative governance. Jinan Journal (Philosophy and Social Sciences Edition), 239(12): 35-49.

[2] Cheng Conghui, 2015, Research on influencing factors of multi-layer hierarchy of emergency command information communication based on ISM. Information Science, 33(12): 56-61.

[3] Wang Bingbing, Xia Zhijie, Yu Liping, 2015, Research on system dynamics simulation of emergency information sharing in online social network. Modern Information, 35(1): 42-48.

[4] Xiao Hua, 2019, Research on information resources sharing for emergency response from the 
perspective of synergy theory. Modern Intelligence, 39(3): 109-114.

[5] Pan Bo, Yu Jie, 2015, Research on information synergy mechanism of public emergency management. Journal of Shanghai Administration College, 16(5): 16-30.

[6] Delone W H, Mclean E R, 1992, Information system success: the quest for the dependent variables. Information Systems Research, 3(1): 60-95.

[7] Kaur H, Sood S K, 2020, Soft-computing-centric framework for wildfire monitoring, prediction and forecasting. Soft Computing, 24(13): 9651-9661.

[8] Zhang Zimin, Zhou Ying, Li Qi, et al., 2010, Information model of emergency response based on information sharing (I): model definition. Chinese Journal of Safety Science, 20(8): 154-160.

[9] Chen Yumei, Zeng Yuexin, 2017, Emergency sharing problems and countermeasure suggestions in China's emergency cooperation. Science and Technology Management Research, (9): 191-195.

[10] Wheaton K J, 2001, Analysis in crisis prevention. International Journal of Intelligence and Counterintelligence, 14(2): 223-231.

[11] Dawes S, Creswella A, Cahan B, 2004, Learning from crisis: lessons in human and information infrastructure from the World Trade center response. Social Science Computer Review, 22(1): 5266.

[12] Netten N, Bruinsmag G, Van S M, et al., 2006, Task adaptive information distribution for dynamic collaborative emergency response. The International Journal of Intelligent Control and Systems, 11(4): 238-247.

[13] Ding Xuefeng, Liu Huchen, 2019, An extended prospect theory-VIKOR approach for emergency decision making with 2-dimension uncertain linguistic information. Soft Computing, 23(22): 12139-12150.

[14] Deng Chunlin, He Zhen, 2014, Research on sharing mechanism of information resources in response to emergencies-taking Hunan Province as an example. Journal of Hunan Institute of Engineering, 24 (3): 1-5.

[15] Pan Bo, Yang Wenting, Yin Pengcheng ,2017, The mechanism of the impact of emergency resource coordination on the construction of linkage information system-analysis based on IS success model. Journal of System Management, 26 (5): 801-808.

[16] Guo Lusheng, Liu Chunnian, 2016, Research on government emergency information resource planning based on EA in big data environment. Information Journal, 35(6): 171-176.

[17] Cheng Shunqi, Wang Shaogu, Chen Chen, et al., 2019, Research on the coordinated linkage mechanism of high temperature heat wave emergency management from the perspective of holistic government. Disaster Science, 34(3): 160-166.

[18] Cai Dongxue, Zhu Jianming, Wang Guoqing, 2017, Research on multi-level collaborative layout of emergency equipment based on scenario analysis. China Management Science, 25 (10): 72-79.

[19] Lin Zhen, 2019, Research on the collaborative governance mechanism of public opinion network for public emergencies. Huazhong University of Science and Technology (Social Science Edition), (2): 38-44.

[20] Cavallo B, de Peretti P, Simonetti B, et al., 2020, Special issue on dynamics of socioeconomic systems: systemic risk-complex systems. Soft Computing, 24(18): 13515-13515.

[21]Bai L B, Chen H L, Gao Q, et al., 2018, Project portfolio selection based on synergy degree of composite system. Soft Computing, 22(16): 5535-5545.

[22] Kou Youguan ,2005, Actively integrate resources to speed up emergency response. Information construction, (6): 17-19.

[23] Xiao Hua, Liu Chunnian, Yin Xiaoli, 2015, Emergency resource information modeling and data modeling: methods and paradigms. Library Science Research, (2): 54-59.

[24] Zheng Bangkun, Lv Xianjing, 2004, Based on the "one-stop" service model and supporting 
platform. Modern Library and Information Technology, (5): 52-54.

[25] Wang Ping, 2014, Research on co-construction and sharing of library information resources based on collaboration theory. Modern Information, (4): 33-37.

[26] Kwon T H, Zmud R W, 1987, Unifying the fragmented models of information systems implementation, critical issues in information systems research. New York: John Wiley: 135-142.

[27] Grover V, Goslar M D, 1993, The Initiation, adoption, and implementation of telecommunication technologies in US. Organizations. Journal of Management Information Systems, 10(1): 141-163.

[28] Hu Ping, Zhang Penggang, Ye Jun, 2007, An empirical study on the factors that affect the information sharing among local government departments. Information Science, 25(4): 548-556.

[29] Sharon S. Dawes, 1996, Interagency information sharing: expected benefit, manageable risk. Journal of Policy Analysis and Management, 15(3): 377-394.

[30] David L, George and Wolken, 2001, Realizing the promise: government information systems and the fourth generation of information technology. Public Administration Review, 61(2): 206220.

[31] Huang Xing, Song Junyi, Li Xing,et al., 2020, Evolutional model of synergy for disaster prevention and reduction in coastal cities. Natural Hazards, 100(3):933-953.

[32] Li Yang, Huang Shuqiang, Fan Rensheng, et al., 2017, Research on gateway deployment of WMN based on maximum coupling subgraph and PSO algorithm. Soft Computing, 21(4):923933.

[33] Su Yi, An Xiaoli, Sun Ying, et al., 2018, Construction and empirical study on the measurement model of regional innovation system coupling degree. Journal of Systems Engineering, 33(3): 398-411. 